\title{
Characterization of Spectral Magnification based on Four-Wave Mixing in Nonlinear Fibre for Advanced Modulation Formats
}

Lillieholm, Mads; Corcoran, B.; Galili, Michael; Grüner-Nielsen, Lars; Oxenløwe, Leif Katsuo; Lowery, A. J.

Published in:

Proceedings of 43rd European Conference on Optical Communication

Publication date:

2017

Document Version

Peer reviewed version

Link back to DTU Orbit

Citation (APA):

Lillieholm, M., Corcoran, B., Galili, M., Grüner-Nielsen, L., Oxenløwe, L. K., \& Lowery, A. J. (2017).

Characterization of Spectral Magnification based on Four-Wave Mixing in Nonlinear Fibre for Advanced

Modulation Formats. In Proceedings of 43rd European Conference on Optical Communication [P1.SC4.65]

\section{General rights}

Copyright and moral rights for the publications made accessible in the public portal are retained by the authors and/or other copyright owners and it is a condition of accessing publications that users recognise and abide by the legal requirements associated with these rights.

- Users may download and print one copy of any publication from the public portal for the purpose of private study or research.

- You may not further distribute the material or use it for any profit-making activity or commercial gain

- You may freely distribute the URL identifying the publication in the public portal 


\title{
Characterization of Spectral Magnification based on Four-Wave Mixing in Nonlinear Fibre for Advanced Modulation Formats
}

\author{
M. Lillieholm(1), B. Corcoran(2,3), M. Galili(1), L. Grüner-Nielsen(4), L. K. Oxenløwe(1) and A. J. Lowery(2,3) \\ (1) DTU Fotonik, Department of Photonics Engineering, Technical University of Denmark, Ørsteds \\ Plads, Building 343, DK-2800 Kgs. Lyngby, Denmark, madsl@fotonik.dtu.dk \\ (2) Department of Electrical \& Computer Systems Engineering, Monash University, Australia \\ (3) Centre for Ultrahigh-bandwidth Devices for Optical Systems (CUDOS), Australia \\ (4) Danish Optical Fiber Innovation, Åvendingen 22A, DK-2700 Brønshøj, Denmark
}

\begin{abstract}
We characterize the performance of $4 \times$ spectral magnification based on four-wave mixing in optimized nonlinear fibres, for 4/8/16-QAM formats, and report >19-nm operational bandwidth. Predominantly OSNR penalties of $\sim 1 d B$ per bit/QAM-symbol from aberrations non-intrinsic to time lenses are observed.
\end{abstract}

\section{Introduction}

Time lens systems based on chirped-pump ${ }^{1}$ fourwave mixing $(\mathrm{FWM})^{2}$, have been shown to enable advanced optical signal processing via the optical Fourier transformation (OFT) ${ }^{3}$, e.g. to process highspeed serial and parallel telecommunication signals ${ }^{4-6}$. The OFT is based on the space-time duality $^{7}$, which describes the equivalence between a thin lens combined with diffraction, and quadratic phase modulation combined with dispersion. In principle, the OFT is transparent to the modulation format, although for non-ideal time lens systems, the performance of sensitive higher-order modulation formats may be more degraded than robust formats. However, previous results have been based on binary or quaternary modulation (often in a single time lens), hence no investigation has been made. Furthermore, the time lens is often implemented using highly nonlinear fibre (HNLF), for the potential to obtain high FWM efficiency. However, the FWM bandwidth is sensitive to fibre dispersion fluctuations, and unlike CW-pumped FWM, the chirped-pump bandwidth can depend significantly on the third-order dispersion, $\beta_{3}$.

In this paper, we investigate the performance of different modulation formats for a $4 \times$ spectral magnification system based on cascaded time lenses $^{8}$. The bit-error rate (BER) is measured for 10-Gbaud, return-to-zero (RZ), 4- (QPSK), 8- and

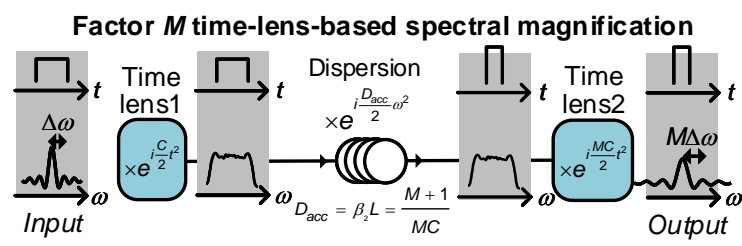

Fig. 1: Operational principle of spectral magnification.

16-QAM signals, for a single carrier (SC) and for 5-channel wavelength division multiplexing (WDM) on a $50-\mathrm{GHz}$ grid. The total operational bandwidth is shown to span $>19 \mathrm{~nm}$, with two time lenses based on FWM in a pair of composite dispersion-flattened HNLF (C-DF-HNLF). The HNLFs were assembled to mitigate dispersion fluctuation effects, by splicing several $50-\mathrm{m}$ pairs, which combine to the desired average dispersion ${ }^{9}$. All considered modulation formats can be processed by the time lens system, and we observe OSNR penalties not intrinsic to the fundamentals of time lens processing. Finally, a $\leq 0.5 \mathrm{~dB}$ penalty for WDM is observed for 4 - and 8-QAM, due to inter-channel FWM.

\section{Principle and setup}

The principle of factor $M$ spectral magnification is shown in Fig. 1. Two time lenses apply a quadratic phase modulation with chirp rates $C$ and $M C$ respectively, separated by an element with accumulated dispersion equal to the sum of the time lens "focal lengths", $D_{a c c}=1 / C+1 /(M C)$. The FWM-based time lens uses flat-top linearly

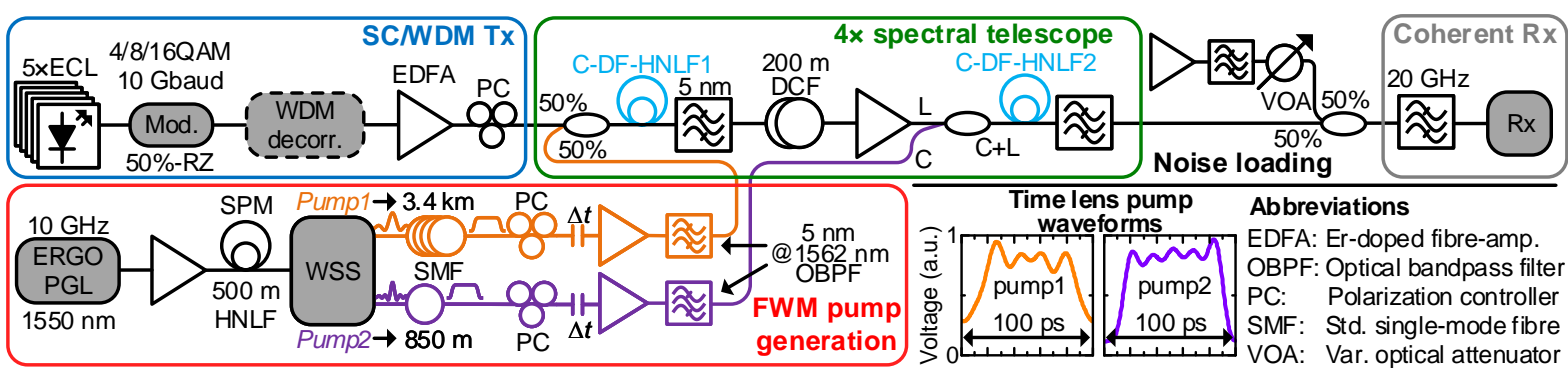

Fig. 2: Experimental setup for $4 x$ spectral magnification of SC or WDM signals. Also shown are traces of pump1 and pump2. 
chirped FWM pump pulses at the same repetition rate as the signal, to impart a parabolic phase onto the generated idler, according to the relation $E_{i}=\eta E_{p}^{2} E_{s}^{*}$. Here subscripts $i, p$, and $s$ denote the idler, pump and signal fields respectively, and $\eta$ is the FWM efficiency term.

The experimental setup for $4 \times$ spectral magnification of WDM and SC signals is shown in Fig. 2. To generate the 5-channel WDM signal, five external cavity laser (ECL) sources on a $50 \mathrm{GHz}$ grid are modulated at $10 \mathrm{Gbaud}$ using an arbitrary waveform generator at $90-\mathrm{GSa} / \mathrm{s}$, thus obtaining $50 \%$ RZ 4-, 8- or 16-QAM modulation. The channels are decorrelated by propagation in $80 \mathrm{~km}$ standard single-mode fibre (SSMF), with subsequent dispersion compensation using a channelized fibre Bragg grating module. Thus, intra-channel dispersion is compensated while inter-channel walkoff is retained. For SC measurements, the decorrelation stage is omitted. To generate the FWM pumps (pump1 and pump2), $\sim 2 \mathrm{ps}$ pulses at $1550 \mathrm{~nm}$ and $10 \mathrm{GHz}$ repetition rate, are generated using an erbium-glass oscillating (ERGO) pulse generating laser (PGL). The pulses are propagated in $500 \mathrm{~m}$ HNLF with zero-dispersion wavelength $\lambda_{0}=1585 \mathrm{~nm}$ and dispersion slope $S=0.017 \mathrm{ps} /\left(\mathrm{nm}^{2} \cdot \mathrm{km}\right)$, to induce spectral broadening by self-phase-modulation (SPM). Rectangular spectra at $1562 \mathrm{~nm}$ are then carved from the resulting frequency comb, with $1.4 \mathrm{~nm}$ and $5.5 \mathrm{~nm} 3-\mathrm{dB}$ widths for pump1 and pump2 respectively, using a wavelength selective switch (WSS). Then, pump1 is chirped by propagation in $3.4 \mathrm{~km}$ SSMF, whereas pump2 is chirped in $850 \mathrm{~m}$ SSMF. The pulses of both pumps obtain $77 \mathrm{ps}$ full-width at half maximum (see Fig. 2). Hence, the chirp rate of pump2 is four times larger than for pump1, as required for $M=4$. The signal and pump1 are combined with $10 \mathrm{dBm}$ and $19.5 \mathrm{dBm}$ power respectively, at the input to CDF-HNLF1 (time lens 1), with length $L=315 \mathrm{~m}$, $\lambda_{0}=1560.4 \mathrm{~nm}, S=0.005 \mathrm{ps} /\left(\mathrm{nm}^{2} \cdot \mathrm{km}\right)$, nonlinear coefficient $\gamma=10.8(\mathrm{~W} \cdot \mathrm{km})^{-1}$ and $2 \mathrm{~dB}$ insertion loss (IL). At the fibre output, the pump and signal are suppressed, and the L-band idler (idler 1 ) is propagated in $200 \mathrm{~m}$ dispersion compensating fibre (DCF), and combined with pump2 in a WDM coupler at the input to C-DF-HNLF2 (time lens 2), with the same parameters as C-DF-HNLF1, except for $L=216 \mathrm{~m}, \lambda_{0}=1559.5 \mathrm{~nm}$ and $1.3 \mathrm{~dB}$ IL. The powers of idler1 and pump2 at the fibre input are $7 \mathrm{dBm}$ and $23 \mathrm{dBm}$ respectively. At the fibre output, the $4 \times$ spectrally magnified signal is noise loaded to enable OSNR sweeps, while the $\mathrm{BER}$ is measured at the coherent receiver, with an $80-G S a / s$ real-time oscilloscope. The noiseloaded OSNR is measured before a $20 \mathrm{GHz}$ $\sim 1.4^{\text {th }}$ order super-Gaussian optical bandpass filter (OBPF), inserted at the receiver.

\section{Results and discussion}

The FWM output spectra for both C-DF-HNLF are shown in Fig. 3(a), given the WDM input. Here, the spectral magnification of 5 WDM channels on a $50 \mathrm{GHz}$ grid, to 5 channels with $200 \mathrm{GHz}$ spacing, is clearly visible. Note the side-lobes of the unmagnified WDM signal ( $27 \mathrm{~dB}$ down), which indicate some inter-channel FWM occurring in time lens 1. FWM spectra at the output of time lens 2 are shown for the SC input moved from $1535 \mathrm{~nm}$ to $1555 \mathrm{~nm}$ in Fig. 3(b). In this case, only signal filter wavelengths are tuned to compensate. The indicated system 3-dB bandwidth is $>18 \mathrm{~nm}$, with $<1.9 \mathrm{~dB}$ conversion efficiency difference measured in time lens 2 . The constellation heat maps (near HD-FEC: $3.8 \times$ $10^{-3} \mathrm{BER}$ ) and the BER vs. OSNR curves, are shown for the central channel $(1550.12 \mathrm{~nm}$ at the input) of the magnified WDM signal and the SC signal $(1550.0 \mathrm{~nm})$ in Fig. 4. Also shown are the BER results with the spectral telescope bypassed (B2B), and the theoretical limits ${ }^{10}$. The OSNR for spectral magnification results was adjusted by $+2.4 \mathrm{~dB}$ to account for additional signal power coming through the $20-\mathrm{GHz}$ OBPF. We note that there is no significant penalty for WDM B2B (B2B-WDM) compared to singlecarrier B2B (B2B-SC), and there is a $<0.9 \mathrm{~dB}$ penalty for B2B compared to the theoretical limit for all formats. For the spectrally magnified single-carrier (SM-SC) case, the penalties are $0.8,1.8$ and $3.0 \mathrm{~dB}$ compared to B2B-SC for QPSK, 8-QAM and 16-QAM respectively. The heat maps do not exhibit significant nonlinear behaviour, and it is observed for 16-QAM that the BER does not depend on the symbol energy. Hence, the penalties originate from impairments
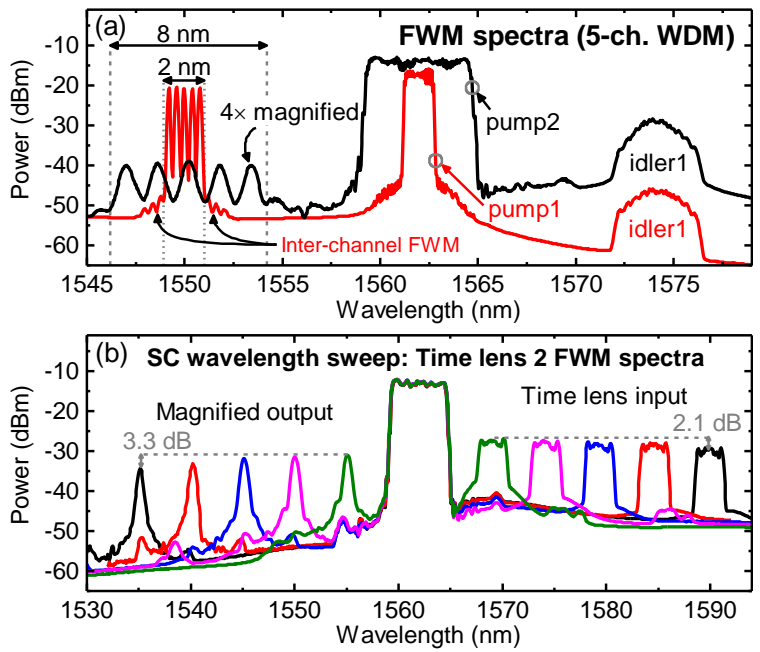

Fig. 3: (a) FWM spectra for time lens 1 (red) and time lens 2 (black) for the WDM input. (b) Time lens 2 output spectra for SC input wavelength sweep from $1535 \mathrm{~nm}$ to $1555 \mathrm{~nm}$. 

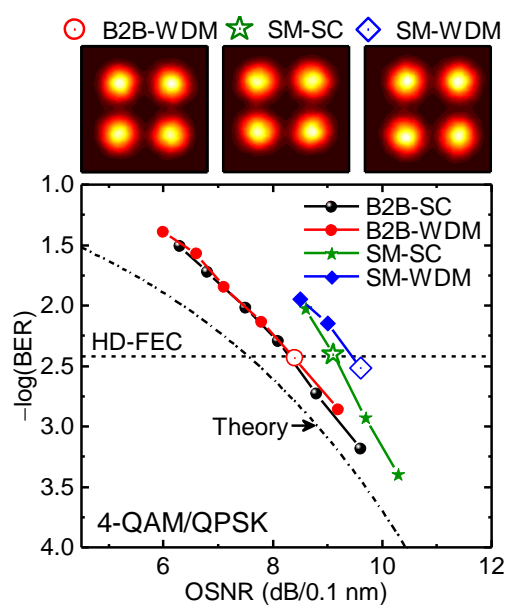
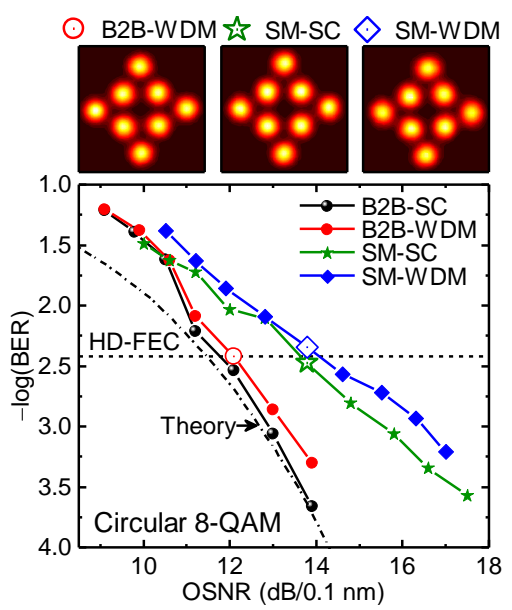
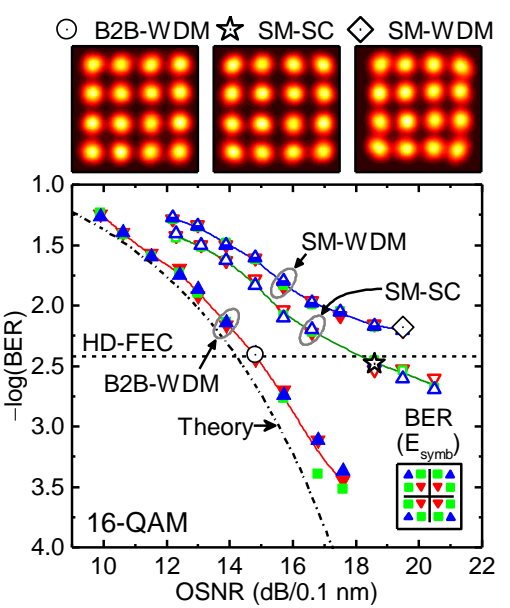

Fig. 4: Constellation heat maps (data-point origin symbol indicated on BER curves) and BER vs. OSNR curves for 4/8/16-QAM. For 16-QAM, B2B-SC results are omitted (no penalty for B2B-WDM compared to B2B-SC), and the symbol-energy-dependent $B E R$ is shown (inset indicates the symbol-to-constellation-point correspondence).

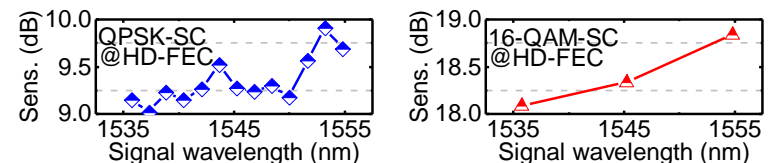

Fig. 5: Single-carrier wavelength dependent sensitivity.

which affect the symbols equally, such as FWM pump noise transfer and time lens aberrations due to imperfect pump pulses, which are not flattop (cf. Fig. 2), or have a non-ideal parabolic phase profile. However, with careful optimization, aberration impairments may be reduced. For QPSK and 8-QAM the SM-WDM penalty compared to SM-SC is $\leq 0.5 \mathrm{~dB}$, which is expected to stem from uncorrelated inter-channel FWM. For a low-dispersion DF-HNLF such FWM may be expected, but the penalty is relatively low compared to the single-carrier implementation penalty, and may be reduced by optimization of the balance between pump and signal powers. Note that for 16-QAM SM-WDM the HD-FEC threshold was not reached; i.e. the heat map is constructed from data with BER considerably above the threshold. Finally, the OSNR sensitivity at the HD-FEC threshold was measured for SC QPSK at wavelengths from $1535.70 \mathrm{~nm}$ to $1554.82 \mathrm{~nm}$ in $200-\mathrm{GHz}$ intervals, and at selected wavelengths for SC 16-QAM. In both cases, there is $<1 \mathrm{~dB}$ sensitivity variation, as shown in Fig. 5.

\section{Conclusions}

We have characterized, for the first time, the performance of spectral magnification as a test case with two FWM-based time lenses, for QPSK, 8-QAM and 16-QAM modulation formats. A $>19 \mathrm{~nm}$ operational bandwidth over most of the C-band, was demonstrated using dispersionoptimized HNLFs, and a modulation format dependent OSNR penalty of $\sim 1 \mathrm{~dB}$ per bit/QAMsymbol was observed, which may be reduced by careful system optimization. Finally, an additional $\sim 0.5 \mathrm{~dB}$ penalty was observed for QPSK and 8-
QAM signals, which is attributed to inter-channel FWM. These results suggest that cascaded time lens systems are applicable for future advanced optical communication systems.

We gratefully acknowledge OFS for the nonlinear fibre. Funding: Danish Council for Independent Research (DFF-4005-00558B), and the ARC (CE110001018).

\section{References}

[1] E. Palushani et al., "Flat-Top Pulse Generation by the Optical Fourier Transform Technique for Ultrahigh Speed Signal Processing," IEEE J. Quantum Electron., vol. 45, no. 11 , p. 1317 (2009).

[2] M. E. Marhic et al., "Broadband Fiber Optical Parametric Amplifiers," Opt. Lett., vol. 21, no. 8, p. 573 (1996).

[3] M. Nakazawa et al., "Ideal Distortion-Free Transmission Using Optical Fourier Transformation and Fourier Transform-Limited Optical Pulses," IEEE Photon. Technol. Lett., vol. 16, no. 4, p. 1059 (2004).

[4] M. A. Foster et al., "Silicon-Chip-Based Ultrafast Optical Oscilloscope," Nature, vol. 456, no. 7218, p. 81 (2008).

[5] H. C. H. Mulvad et al., "Ultra-High-Speed Serial-toParallel Data Conversion by Time-Domain Optical Fourier Transformation in a Silicon Nanowire," Opt. Express, vol. 19, no. 26, p. B825 (2011).

[6] P. Guan et al., "16 Channel WDM Regeneration in a Single Phase-Sensitive Amplifier through Optical Fourier Transformation," Proc. ECOC, Th.3.B.3., (2016).

[7] B. H. Kolner, "Space-Time Duality and the Theory of Temporal Imaging," IEEE J. Quantum Electron., vol. 30, no. 8, p. 1951 (1994).

[8] P. Guan et al., "All-Optical OFDM System using a Wavelength Selective Switch based Transmitter and a Spectral Magnification based Receiver," Proc. ECOC, $p$. 1 (2014).

[9] M. Lillieholm et al., "Dispersion-Flattened Composite Highly Nonlinear Fibre Optimised for Broadband Pulsed Four-Wave Mixing", Proc ECOC, p. 330 (2016).

[10] R.-J. Essiambre et al., "Capacity Limits of Optical Fiber Networks," J. Lightwave Technol., vol. 28, no. 4, p. 662 (2010). 